\title{
Circulating multi car lift system - traffic concept and analysis
}

\author{
Stefan Gerstenmeyer ${ }^{1,3}$, Richard Peters ${ }^{2,3}$ \\ ${ }^{1}$ thyssenkrupp Elevator Innovation $\mathrm{GmbH}$, \\ Bernhäuser Str. 45, 73765 Neuhausen, Germany \\ stefan.gerstenmeyer@thyssenkrupp.com \\ ${ }^{2}$ Peters Research Ltd, \\ Boundary House, Missenden Road, Great Kingshill, Bucks HP15 6EB, UK \\ richard.peters@peters-research.com \\ ${ }^{3}$ School of Science and Technology, The University of Northampton, UK
}

\begin{abstract}
A new generation of lifts currently under development applies magnetic linear propulsion and does not need ropes. Shafts are shared, and lifts move in two or more dimensions. Taller and more densely populated buildings will be accommodated by adding more cars but not necessarily more shafts. Engineers planning lift installations need new ways to assess the handling capacity and quality of service provided by ropeless lifts. In this paper possible traffic concepts are considered as well as some traffic design principles being established by applying simple cycle time calculations. For example, shuttle lift applications are considered and compared with current roped solutions. Improving on cycle time calculations requires the development of dispatching strategies, the modelling of safety distance requirements and traffic simulation models; an overview of progress in these areas will be presented.
\end{abstract}

Keywords: Ropeless lifts, multi car, magnetic linear propulsion, handling capacity, quality of service, simulation, safety distance

\section{INTRODUCTION}

The article is based on the paper "Lifts without ropes: how many shafts and cars are needed?" which was originally published and presented at the Symposium on Lift and Escalator Technologies 2015 in Northampton [1]. Chapter 3 "Traffic concept" was originally published and presented at the CTBUH conference 2015 in New York [2].

The number of roped lifts in known lift systems is limited to one or two cars in one shaft as the suspension ropes of the lower car need to be diverted around the upper car [3]. Putting more than two cars in one shaft is limited because of the space needed by the ropes. Also traffic handling efficiency is limited by putting more than two cars in one shaft as it becomes more difficult for all cabins to serve the main entrance floors. Using a shaft for both up and down travel means that the cars need to wait until all of the cars have reversed their direction of travel, which is a constraint to improving performance. Having multiple cars circulating in at least two shafts with one shaft being used for travelling in the up direction and the other shaft for travelling in the down direction enables improvements in performance and efficient shaft usage. An early example is the paternoster which was the first realisation of a circulating lift system [4]. However, the continuous slowly circulating chain of open cabins, with no cabin or shaft doors has limitations in travelling time, safety and transportation of handicapped passengers. Assuming a cabin to cabin distance of 3 metres, a velocity of about $0.3 \mathrm{~m} / \mathrm{s}$ [5] and two passengers per cabin the handling capacity (HC5) of a paternoster is about 60 passengers $/ 5$ minutes.

For new and safe circulating multi car lift systems (MCLS) linear motors installed in the shaft lifting multi individual and independent cars are one of the main enabling technologies. The concept and idea of a circulating multi car lift system with independent moving cars is not new in the lift industry [6]. 
Simple traffic calculations of a circulating lift system were published based on technical assumptions as there were unanswered technical and economic questions [7]. Technical challenges using lifts without ropes/counterweights and opportunities in building efficiency for circulating lift systems were discussed [8]. Also, advanced two dimensional traffic systems that include horizontal passenger movement were analysed $[9,10]$.

To realise a circulating MCLS different technical challenges need to be solved. A propulsion system to propel multiple independent moving cars in multiple shafts is necessary as well as a guiding system for the cars including exchanger units to move cars between shafts horizontally. Lightweight cabin designs enable an economical system. A certified safety system including safety brakes needs to ensure that there is no collision.

Engineers planning lift installations need new ways to assess the handling capacity and quality of service provided by circulating MCLS. In this paper traffic design principles are established by applying simple cycle time calculations considering safety distance constraints. As an example, shuttle lift applications are considered and compared with a current circulating MCLS solution.

\section{DEFINITIONS}

INT

MCLS

$N_{C}$

$N_{S}$

$P$

RTT

$t_{A r r}$

$t_{c}$

$t_{C y}$

$t_{C y E x}$

$t_{C y F 2}$

$t_{C y R}$

$t_{\text {Dep }}$

$t_{d w e l l}$

$t_{E x}$

$t_{o}$

$t_{p}$ interval between two cars departing from the main floor [s]

multi car lift system

number of cars in a multi car systems

number of multi car systems

number of passengers in a car

round trip time of a car [s]

arrival time of a car at a landing after a previous car departure [s]

door closing time (before a car departs a landing) [s]

minimum possible cycle time in a multi car loop/system [s]

minimum cycle time at an exchanger landing [s]

minimum cycle time at an intermediate stop where two subsequent cars are stopping [s]

real cycle time of a multicar system $[\mathrm{s}]$

departure time of a car from a landing before a following car can arrive [s]

door dwell after passenger detection clearance and before doors start closing [s]

exchanger preparation time for $90^{\circ}$ rotated movement $[\mathrm{s}]$

door opening time (after car has arrived at a landing) [s]

transfer time of a passenger to enter or exit the cabin [s] 
$t_{s 2 s}$

$t_{\text {Stand }}$

UPPHC time between a first car departing for a floor until the subsequent car can stop at the floor $[\mathrm{s}]$

standing time of a car at a landing [s]

up peak handling capacity [passengers per 5 minutes]

\section{TRAFFIC CONCEPT}

\subsection{Current concepts}

A classical approach in high-rise buildings to reduce the footprint of lift equipment is to divide the building in different zones (see Figure 1(a)). Each zone is served by a lift group dedicated to a specific zone. If all lifts do not serve all of the floors in the building, core space can be reduced in the upper floors and low rise lifts can be provided at lower velocities [5]. Dedicating lift groups to zones reduces the number of probable stops. Based on the roundtrip time calculations; reducing the number of stops reduces the roundtrip time [11]; this can reduce the total number of necessary lifts. Lift groups for upper zones can have an express zone. Fast lifts are necessary to travel long distances and achieve necessary group handling capacities, waiting times, and time to destinations. Additionally, an installation with double entrance lobbies reduces the necessary footprints for lifts. Double deck lift cars and two independent cars in one shaft make it possible to improve shaft efficiency. The latter provides higher individual flexibility and can be seen as lift groups of two zones, located within the same shaft. Regardless, there are limits in vertical transportation planning if no interzone transfer floors are used [12].

A state-of-the-art approach includes using sky lobbies as transfer floors into the vertical transportation planning (see Figure 1 (b)). Local groups serving dedicated zones from a sky lobby are stacked, and express shuttle lifts serve the passenger demand between the ground lobbies and the sky lobbies. Vertical transportation concepts with interzone transfer floors can save lift shaft space [13] and the shuttle arrangements can be realized with single or double ground lobbies. The latter requires the use of two cabins in one shaft, mechanically coupled as double decker or two independent cars. Also, escalators connecting the ground lobbies may be necessary. Local groups can be single cabin shafts or multi-cabin shafts. A traffic concept using a circulating MCLS is indicated in Figure 1(c). 


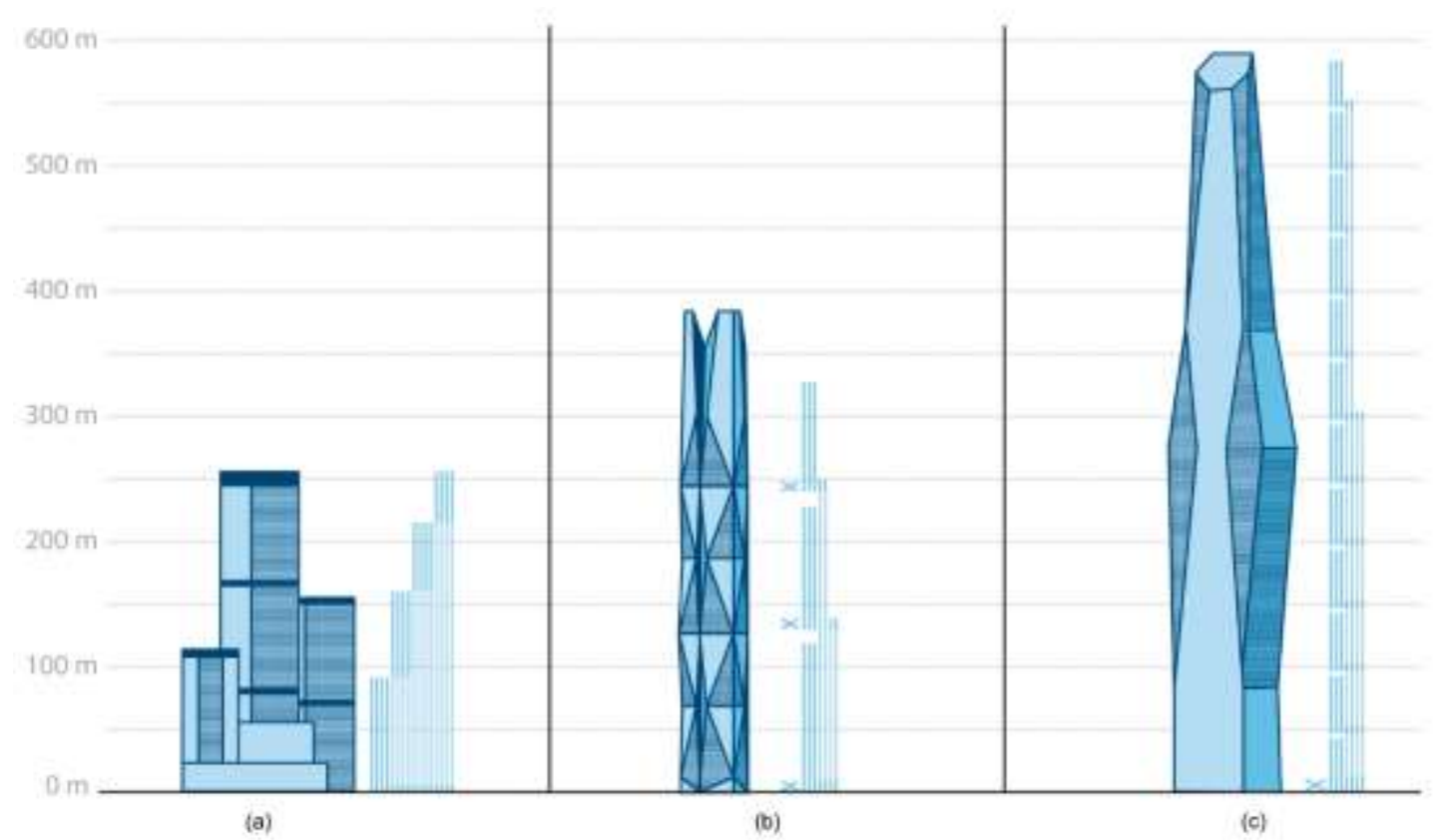

Figure 1: Comparison of different traffic concepts

\subsection{Next generation vertical transportation concepts}

Shuttle and sky lobby arrangements using traditional single or double deck lifts do have limits and disadvantages in shaft efficiency. Still, only one or two cars or cabins use a long single lift shaft. In mega high-rise buildings, lifts are getting faster to keep the journey time to a minimum and to provide an adequate quantity and quality of service with a minimum number of shuttle lifts. Limits in speed are related to human comfort regarding differential ear pressure. Limits in travel height are related to the maximum possible length of hoist cables. A circulating ropeless MCLS eliminates the limits and disadvantages of traditional shuttle lifts and also enables more flexible arrangements. Some simple examples will demonstrate options and flexibility.

There are different options for simplified traffic concepts, including a circulating MCLS such as a shuttle with a single ground lobby (see Figure 2). Different multi car loops can be assigned to different zones in the building (S1). A multi car loop can serve one or multiple sky lobbies, thus it can be assigned to multiple building zones (S2). Multiple multi car loops can be combined to a group serving the same zone(s)/sky lobbies in the building (S2).

Local lift groups can be stacked as single car groups (L2) or groups of two independent cars in a single shaft having distributed lobbies for the lower and the upper cars (L1). This enables direct inter-zone traffic. 


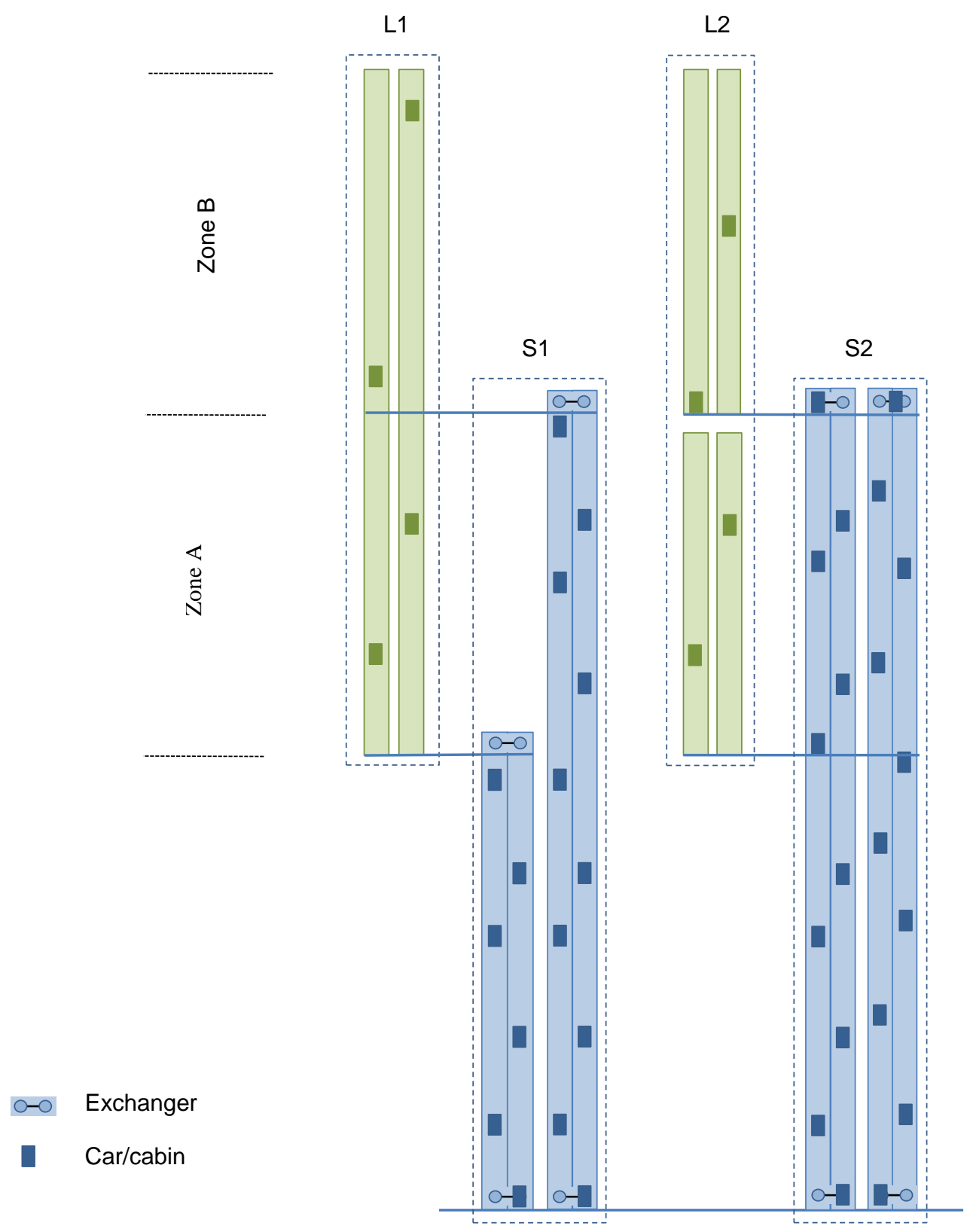

Figure 2: Options of simplified traffic concepts, including a circulating MCLS as a shuttle with a single ground lobby

There are different options of simplified traffic concepts, including a circulating MLCS such as a shuttle with a double ground lobby (see Figure 3). There are two options for a sky lobby arrangement: A double sky lobby (S3) and a pair of distributed sky lobbies (S4). In case of a double ground lobby arrangement, each ground lobby as well as the two highest sky lobbies will be equipped with an exchanger unit. This requires an exchanger unit somewhere in the middle of the shafts. Similar to a single ground lobby configuration, different multi car loops can be assigned to different and multiple zones in the building. This means a multi car loop can serve multiple, double sky lobbies or multiple pairs of distributed sky lobbies (S5), similar to solution (S2). 
Local lift group options for pairs of distributed sky lobbies are similar to the single ground lobby arrangement. Additional options for local groups are possible with a double sky lobby. Similar to local groups in double decker shuttle concepts, a double deck or two independent cars in one shaft can be used as a local group (L3).

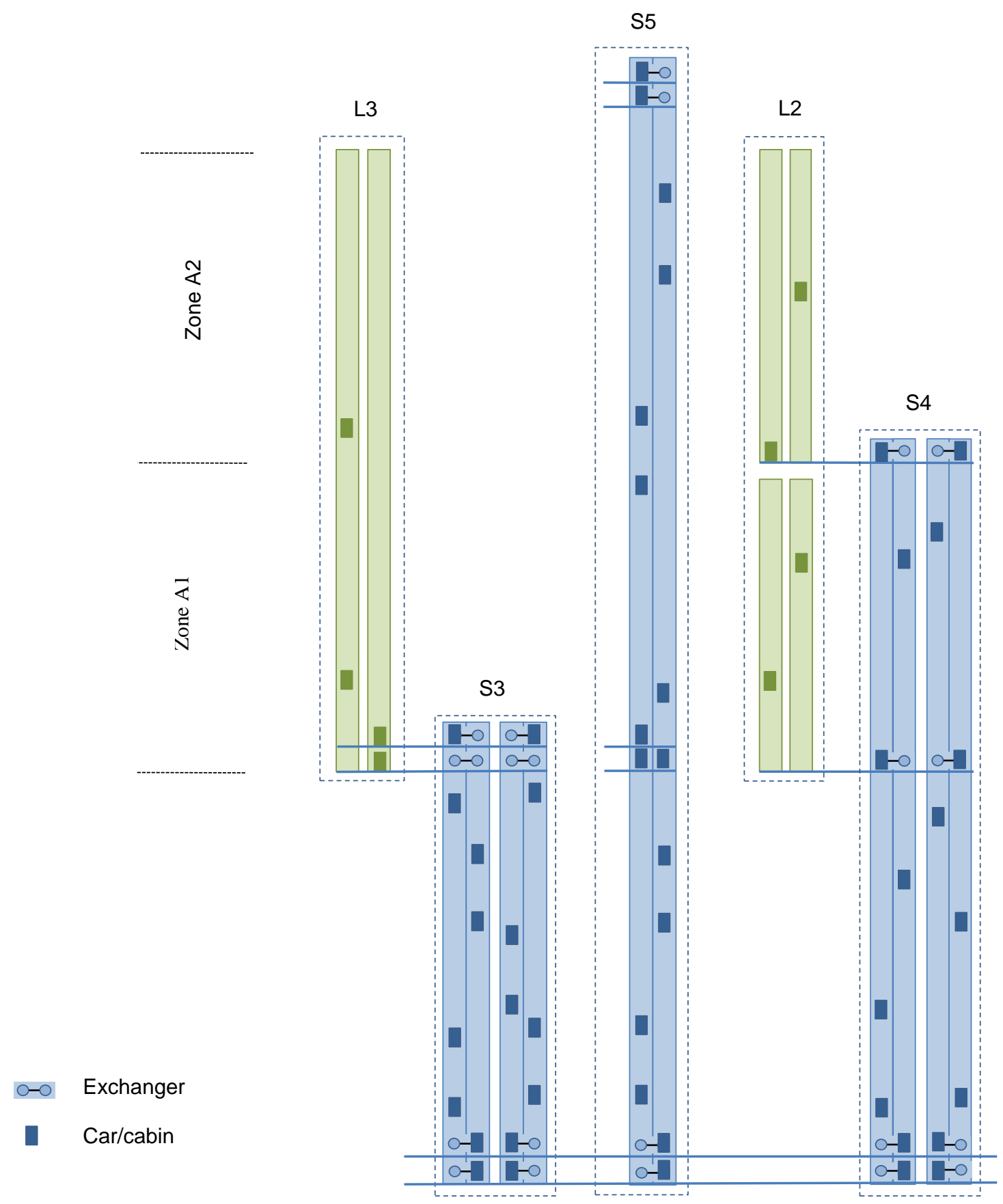

Figure 3: Options of simplified traffic concepts including a circulating MCLS as a shuttle with a double ground lobby 
Spatial plots of one pair of cabins shows how a pair of cabins move within the shafts. Travel in the up direction is in a different shaft from the down direction.

Figure 4 show the spatial plot of a pair of cars, D1a(t) and D1b(t), in a circulating MCLS with a pair of distributed sky lobbies like the arrangement in (S4).

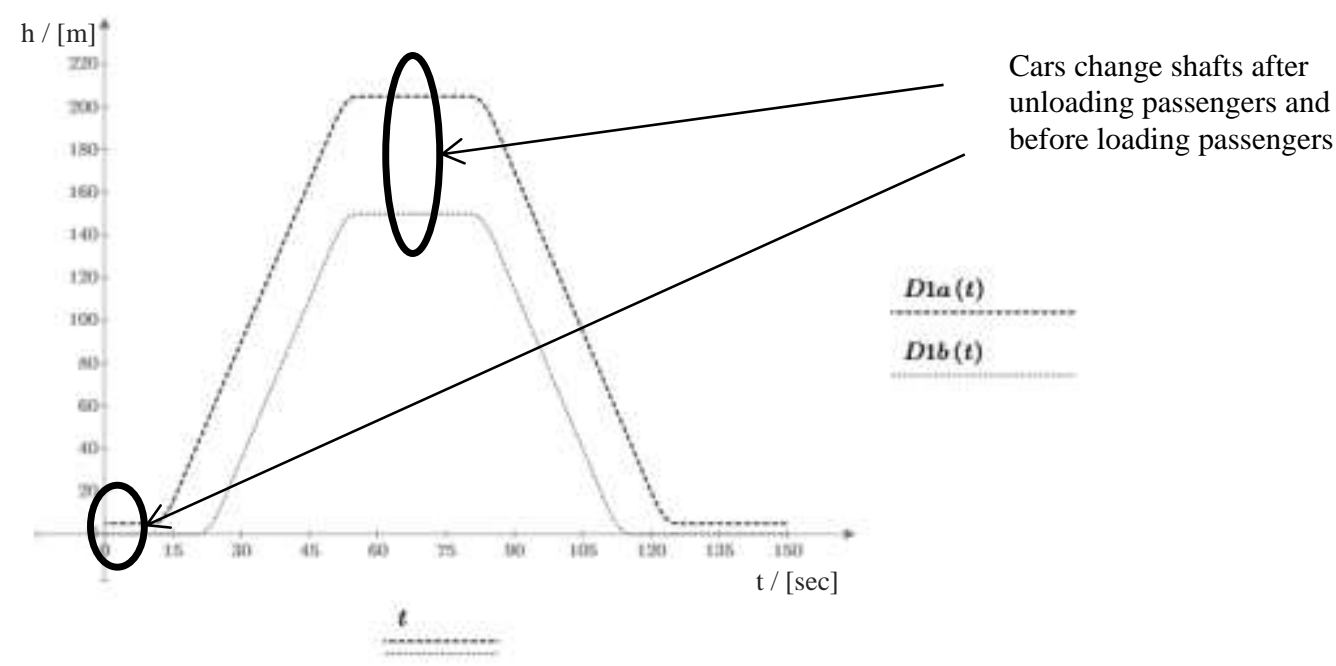

Figure 4: Spatial plot of two cars with a pair of distributed sky lobbies

Figure 5 shows the spatial plot of a pair of cars, D1a(t) and D1b(t), in a circulating MCLS with two pairs of distributed sky lobbies similar to the arrangement in (S5), which has two double sky lobbies. A multi car loop can be assigned different zones with different pairs of distributed sky lobbies.

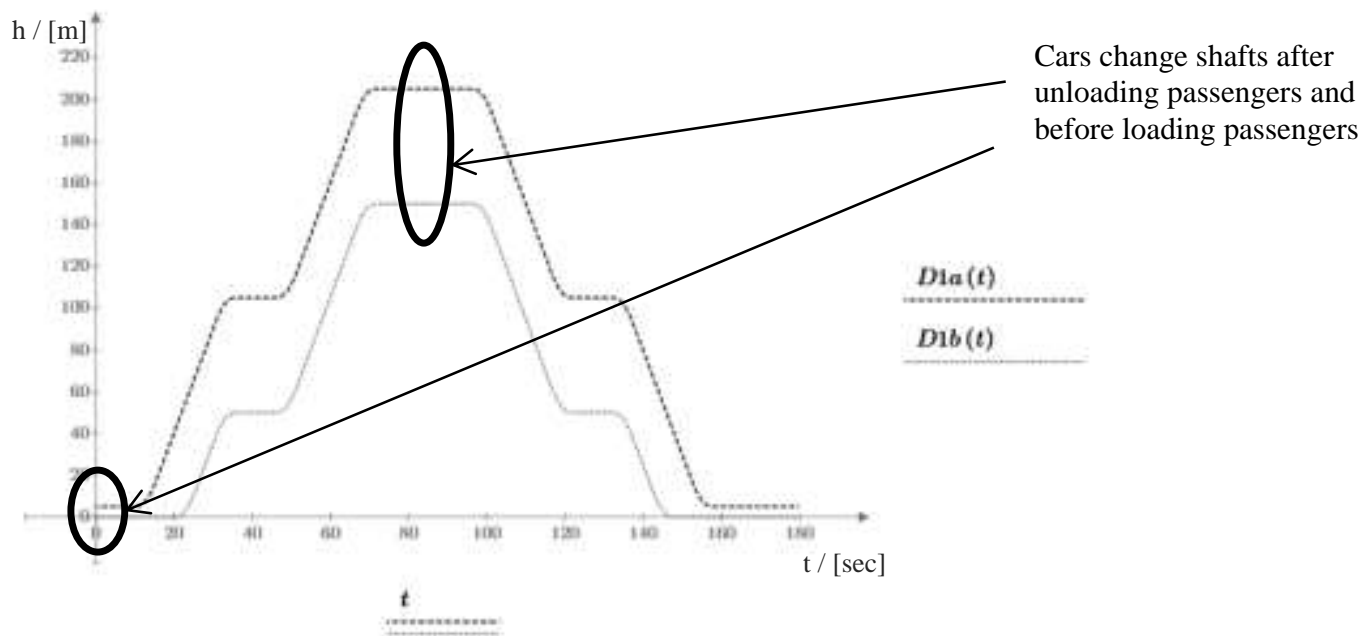

Figure 5: Spatial plot of two cars with two pairs of distributed sky lobbies 
The arrangement of vertical transportation for vertical cities can be compared with horizontal transportation. The shuttle lifts are like little intercity trains connecting the main stations - the sky lobbies. The local lift groups are like the local transportation with a bus or underground metro. The circulating inter-lobby lift system enables flexible arrangements in vertical transportation concepts, is not limited to the examples and options shown, and is not limited in height.

\section{CIRCULATING ROPELESS MULTI CAR LIFTS}

In 2014, a ropeless lift system where multiple lift cars are travelling in the same shafts and are able to change vertical shafts horizontally was unveiled [14]. Multiple, independent lift cars circulating safely in multiple shafts (loops) (see Figure 6). Different technical innovations and solutions solve technical challenges to realise a circulating MCLS and are briefly mentioned in this section [2]. A $1: 3$ scaled model of the lift system is running in Spain $[15,16]$.

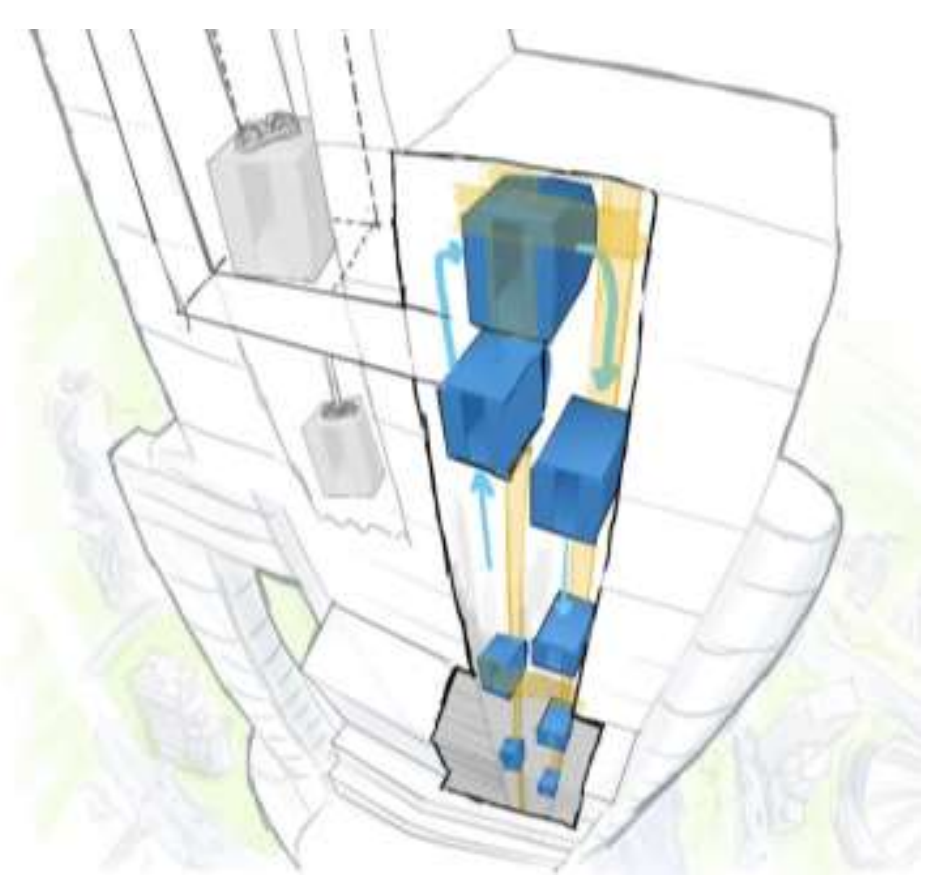

Figure 6: A circulating ropeless MCLS

Propulsion system: Linear motors propel multiple independent moving cars in multiple shafts. Segments of coil units driven by multiple frequency inverters are mounted in the shafts while magnet jokes are mounted on the cars. The same propulsion system is used for horizontal movement.

Lightweight cabin: Lightweight cabin designs for eight passengers enable an economical system. Heavy steel constructions are replaced by a carbon composite design to reach lightweight targets.

Guiding of lift cars and exchangers: A backpack solution guides cars and enables exchanger units to move cars between shafts horizontally. The exchanger is realised by $90^{\circ}$ rotating shaft elements.

Safety: A certified safety system ensures that there is no collision and shaft doors are monitored. New brake concepts are necessary and including the propulsion system into the safety concept helps to improve safety. 
Additional advantage: Vibration of tall buildings e.g. excited by strong winds can excite lift ropes sway especially if natural frequencies coincide. Rope sway with large amplitudes may cause major problems and damage [17]. With ropless lifts these problems do not exist.

\section{MINIMUM POSSIBLE CYCLE TIME}

The number of passengers arriving at a specific lobby that can be transported by the MCLS within a specific time can be calculated by the number of departing full cabins. The time between two subsequent cars is the cycle time.

\subsection{Cycle time}

The cycle time in a MCLS is the time between the departure or arrival of two subsequent cars. It can also be defined as the time between two subsequent cars passing a specific position in the shaft travelling at the same speed and in the same direction.

Figure 7 shows the vertical positions over time of two subsequent cars $D_{V C a r}(t)$ and $D_{V C a r}(t)$. Both cars are travelling in the up direction in the first shaft, are changing shafts at the top floor at $100 \mathrm{~m}$ and are travelling in down direction in a second shaft. While car 1 has already changed to the down direction shaft car 2 is arriving at $100 \mathrm{~m}$ in the up direction shaft. At the bottom floor the cars are changing shafts again. Both cars are stopping in each direction at an intermediate floor at the $50 \mathrm{~m}$ level. The time between car 1 and car 2 is the cycle time. For a better overview the position of additional cars travelling in the MCLS is not shown. As the minimum possible cycle time is limited by the minimum distance during a complete round trip of the cars, critical situations need to be considered in detail. It is obvious that only one car can be at a specific position at the same time. If cars are travelling they are changing position continuously and make the position available for the next car. If cars are standing only one car can be at that position for the time the car is located at that position. To find the minimum possible cycle time over a complete round trip the stops of the cars need to be analysed in detail.

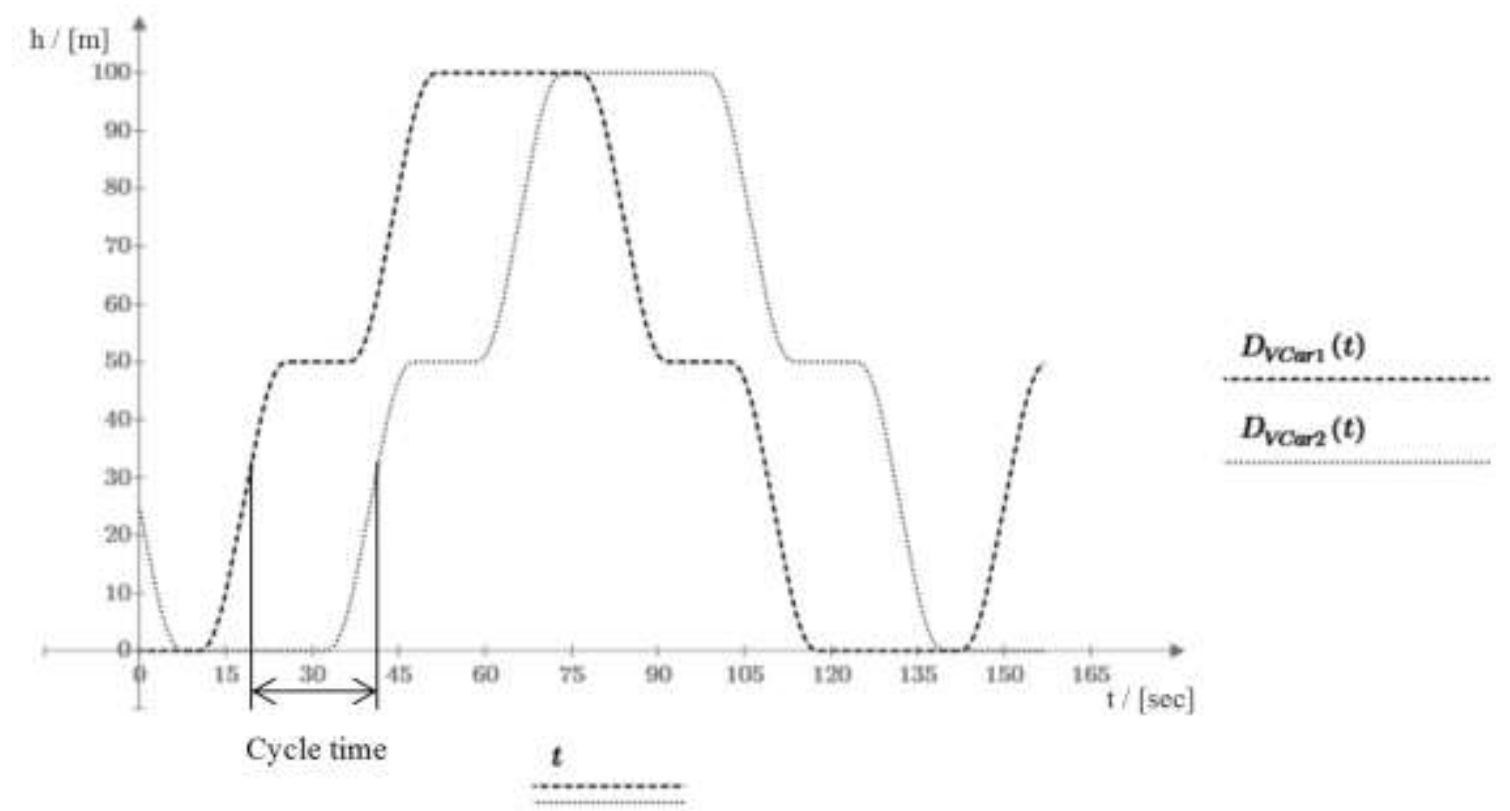

Figure 7: Vertical position of two subsequent cars 


\subsection{Safety distance constraints}

To define the minimum possible cycle time between cars in a MCLS safety distance constraints need to be considered. There must be minimum distance between cars at any time during normal operation. The control system responsible for an optimised handling capacity in 5 minutes (HC5) and quality of service needs to consider this minimum distance. A certified safety system triggers an emergency stop of the cars in case of violated safety distances. In addition, by enabling a controlled stop of the cars the control system monitors positions and movements of the cars and decelerates cars in unexpected situations without triggering the emergency stop. The controlled stopping of the cars includes the same or higher jerk and deceleration rates than normal operation rates.

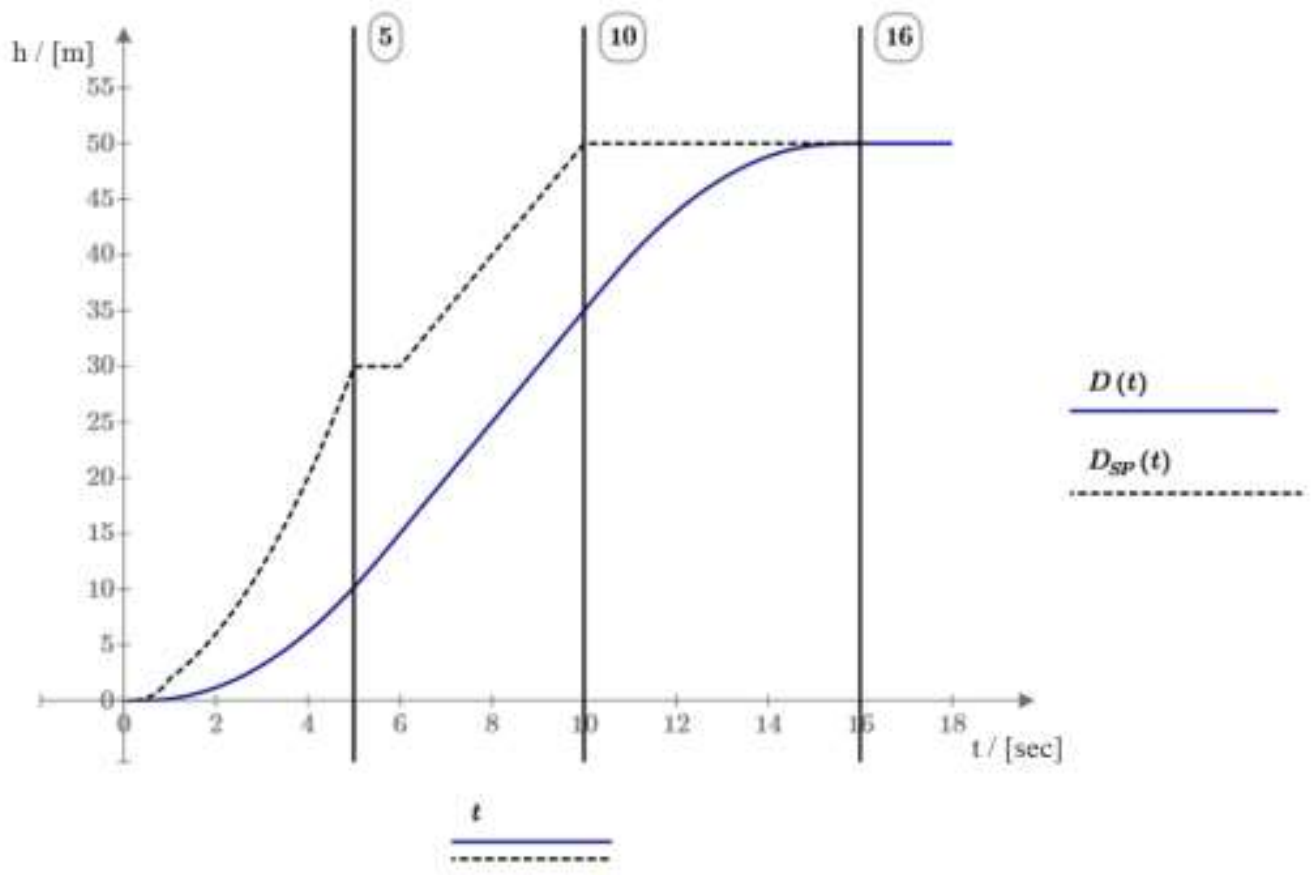

Figure 8: position $(\mathrm{D}(\mathrm{t}))$ and stopping point $\left(\mathrm{D}_{\mathrm{SP}}(\mathrm{t})\right)$ of a car

A stopping distance and a stopping point of the controlled deceleration can be calculated at any time [18]. In case of violating any minimum distances between cars, the cars can be stopped by executing controlled deceleration. Figure 8 shows the position of a car over time $(D(t))$ and the stopping point $\left(\mathrm{D}_{\mathrm{SP}}(\mathrm{t})\right)$ after a spontaneous controlled deceleration with rated deceleration values. The stopping point $\left(\mathrm{D}_{\mathrm{SP}}(\mathrm{t})\right)$ in Figure 8 shows the position where the car comes to a standstill if the controlled deceleration with rated values is triggered at time $t$ while the lift is moving on its normal run $(\mathrm{D}(\mathrm{t}))$ from $0 \mathrm{~m}$ to $50 \mathrm{~m}$. If the lift is in the deceleration process to the $50 \mathrm{~m}$ level $(10 \mathrm{~s}-16 \mathrm{~s})$ the spontaneous controlled deceleration cannot stop the car earlier if the rated values for deceleration and jerk are used. This is represented by the constant stopping point $\left(\mathrm{D}_{\mathrm{SP}}(\mathrm{t})\right)$ at the destination position $(50 \mathrm{~m})$ between $10 \mathrm{~s}$ and $16 \mathrm{~s}$. The stopping point is also constant if a spontaneous deceleration is started during the end of the acceleration process $(5 s-6 s)$ while the acceleration is reduced by a negative jerk. The controlled deceleration can also be operated with higher values for deceleration and jerk. To calculate a safe position of another car a minimum distance which includes the car height needs to be added to the stopping position.

\subsection{Exchanger}

To analyse the stop at an exchanger unit the design of the exchanger unit and the process of exchanging cars between shafts needs to be considered. The analysis is based on a backpack solution including the linear motor and car guidance [2]. The shaft elements are able to rotate by $90^{\circ}$. Cars can move horizontally. Passengers can load and unload during the rotation process since 
the cabin is held in an upright position. Figure 9 shows a simple example of the functionality of the exchanger unit.
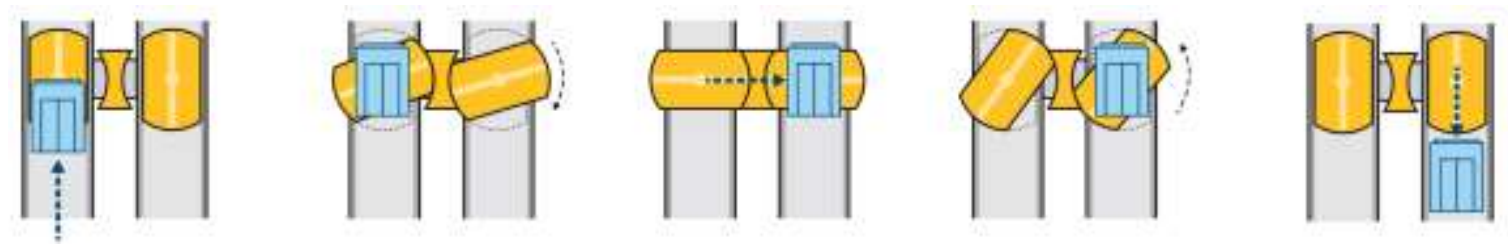

Figure 9: Exchanger functionality

\subsection{Calculation of the minimum possible cycle time}

As the bottle neck of the minimum possible cycle time $\left(t_{C y}\right)$ is when cars are stopping, these are the situations analysed. This includes the stops at the exchanger units and intermediate stops where both cars are stopping successively.

Cycle time at an exchanger landing: The minimum cycle time at an exchanger landing $\left(\mathrm{t}_{\mathrm{CyEx}}\right)$ with passengers loading and unloading can be calculated with equation (1).

The passenger transfer during the standing time $\left(\mathrm{t}_{\text {Stand }}\right)$ of the cabin can be done in parallel to the exchanger preparation time $\mathrm{t}_{\mathrm{Ex}}$ (rotation of the shaft element) for the following horizontal or vertical movement.

$$
t_{C y E x}=t_{\text {Arr }}+\max \left(t_{\text {Stand }}, t_{E x}\right)+t_{D e p}+t_{E x}
$$

After the time a previous/front car has departed from the exchanger unit $\left(t_{\text {Dep }}\right)$ the next car arrival time $\left(t_{\text {Arr }}\right)$ is the time that it takes a car to arrive after the time the exchanger unit has been prepared for the next car $\left(t_{E x}\right)$. A long car arrival time $\left(t_{\text {Arr }}\right)$ for the next car may enable the parallel preparation of the exchanger after the previous/front car has departed the exchanger landing.

The standing time ( $\left(t_{S t a n d}\right)$ is calculated with equation (2) and includes passenger transfer times $\left(t_{p}\right)$, average number of passengers in the car $(P)$ and door times (door open time: $t_{0}$, door dwell: $t_{d w e l l}$, door closing time: $t_{c}$ ).

$$
t_{\text {stand }}=t_{o}+P t_{p}+t_{d w e l l}+t_{c}
$$

Cycle time at an intermediate floor (both stopping): The minimum cycle time at an intermediate floor with two subsequent cars stopping at the same floor $\left(t_{\mathrm{CyF} 2}\right)$ can be calculated with equation (3). The time between departure of the front car 1 and the arrival of the following car 2 (start to stop time $t_{\mathrm{s} 2 \mathrm{~s}}$ ) depends on the stopping distances and minimum distances between cars and is shown in Figure 10. The safe position for car 1 in relation to car 2 is shown with $\mathrm{D}_{2 \mathrm{SfP}}(\mathrm{t})$ and depends on the position, stopping point of a controlled deceleration with rated values of car 2 and an additional minimum distance between car 2 and car 1 . The safe position must not touch the position of car 1 .

$$
t_{C y F 2}=t_{\text {Stand }}+t_{s 2 s}
$$




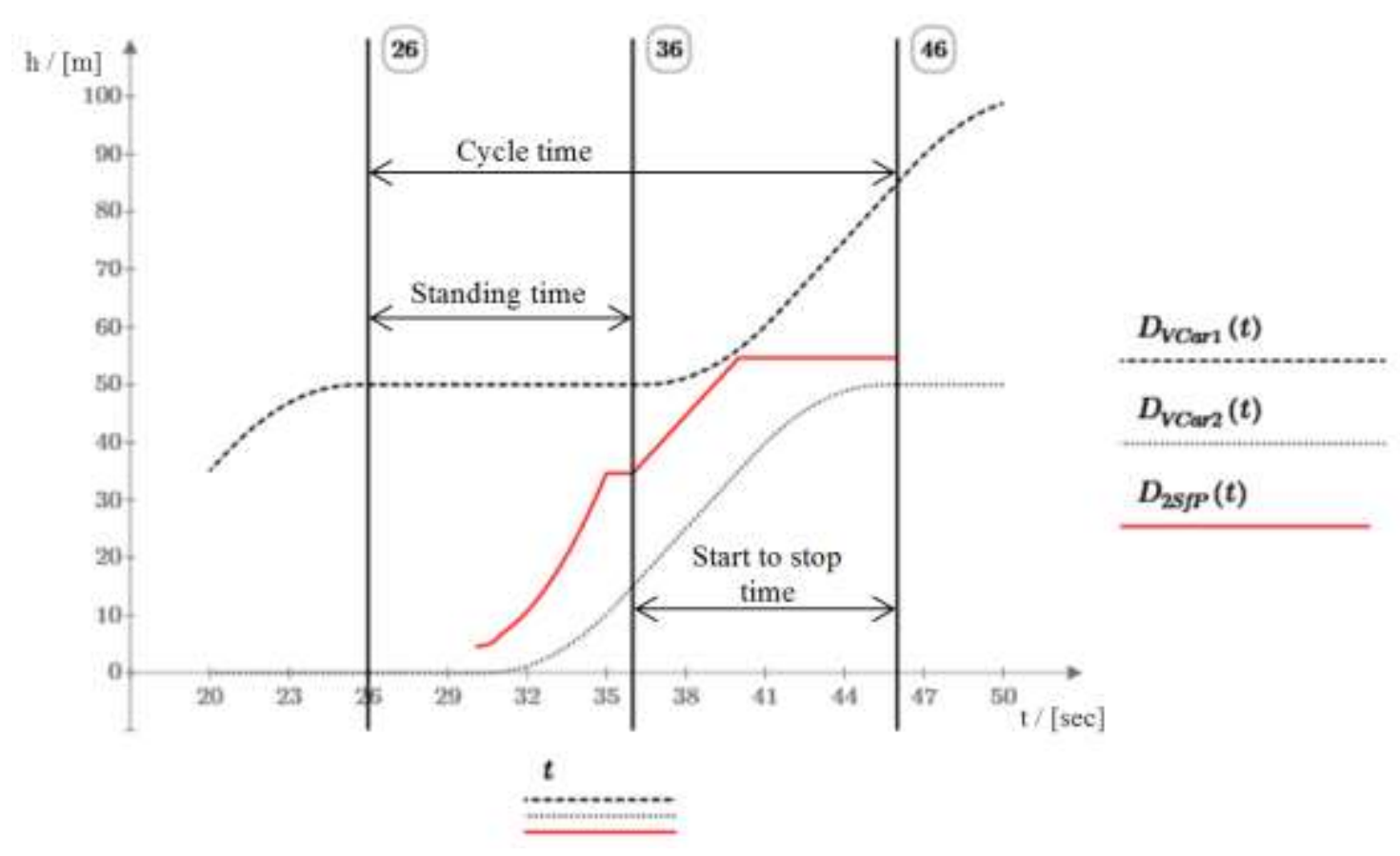

Figure 10: Cycle time at an intermediate floor

The situation with the longest minimum cycle time is the minimum possible cycle time of the MCLS and is defined with equation (4).

$$
t_{C y}=\max \left(t_{C y E x}, t_{C y F 2}\right)
$$

\section{HANDLING CAPACITY}

To use a circulating multi car system in a vertical traffic concept, it is necessary to know the handling capacity in 5 minutes (HC5). As the lift system is different in comparison to traditional lift systems, the known equations need to be adapted to the new system.

\subsection{General}

The handling capacity for incoming passengers can be calculated with the simple equation for conventional lifts using the interval (INT) and number of passengers per cabin (P) (see equation (5)) [11]. This is also true for a circulating MCLS.

$$
U P P H C=\frac{300 s * P}{I N T}
$$

The interval (INT) of a group of circulating MCLS is defined by the average cycle time $\left(t_{\mathrm{Cy}}\right)$ and the number of MCLSs $\left(\mathrm{N}_{\mathrm{S}}\right)$ (see equation (6)).

$$
I N T=\frac{t_{C y}}{N_{S}}
$$

The handling capacity for incoming passengers in an up direction is independent from any down traffic or traffic between upper floors (e.g. sky lobbies). Additional down traffic will affect the RTT of a cabin because of passenger transfer times and door times of existing or additional stops. If the RTT of the cabins change/increase then the number of cabins or the speed of the cabins need to be 
adapted accordingly in order to keep the average cycle time between subsequent cars to a constant value.

\subsection{Cabin size}

Increasing the cabin size will increase the handling capacity especially in shuttle applications. However in shuttle applications the HC5 is not a linear function of the cabin size. Doubling the cabin size does not double the HC5 as passenger transfer times and cycle times increase.

\subsection{Double entrance}

As handling capacity is limited by the passenger loading and unloading time, double entrance lobbies (two lobbies above each other) enable simultaneous loading of two cabins which increases the handling capacity. For a circulating MCLS each entrance level may have an exchanger unit enabling a parallel exchanging of two cars (see Figure $3-\mathrm{S} 3$ ). The cycle time is now measured between two pairs of cars (see Figure 11), therefore double the number of passengers can be transported per cycle time. The cycle time will increase slightly since the arrival time and the departure time of two cars at a double lobby/floor is longer compared to a single car stopping at a single floor.

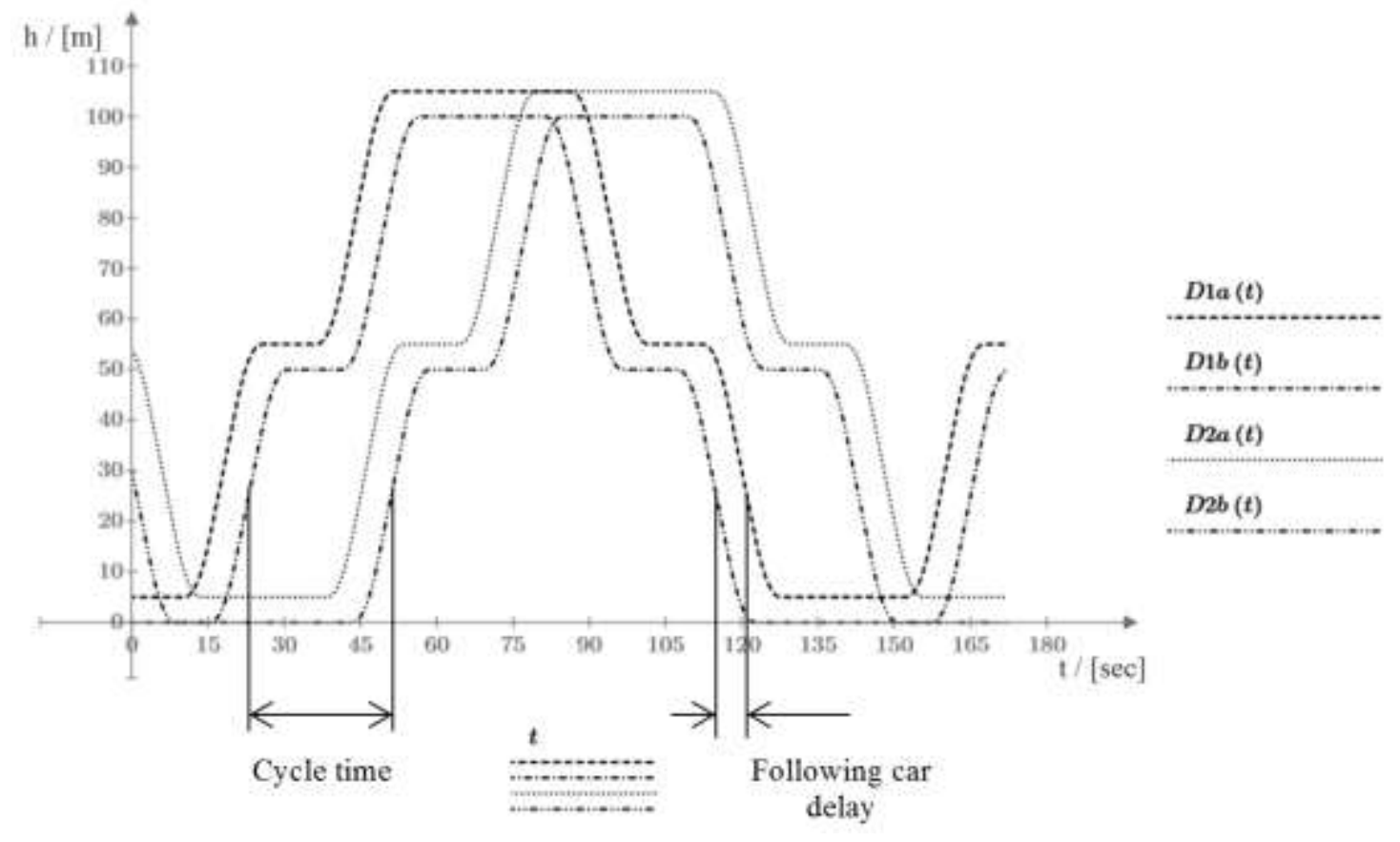

Figure 11: Cycle time between two pairs of cars

\section{NUMBER OF CABINS}

The number of cabins $\left(\mathrm{N}_{\mathrm{C}}\right)$ in a circulating MCLS depends on the round trip time (RTT) and the cycle time $\left(\mathrm{t}_{\mathrm{Cy}}\right)$. It can be calculated with equation (7).

$$
N_{C}=\frac{R T T}{t_{C y}}
$$

This is also illustrated with Figure 12. It shows a complete round trip of a car (D1(t)). The round trip time is divided by the cycle time and shows every position of the car after a period of the cycle time. These positions equal the current position of the other cars in the MCLS at time $t=0$ which is 
shown with the two shafts of a MCLS in Figure 12. With double entrance configurations and pairs of cars the number of cars is doubled.

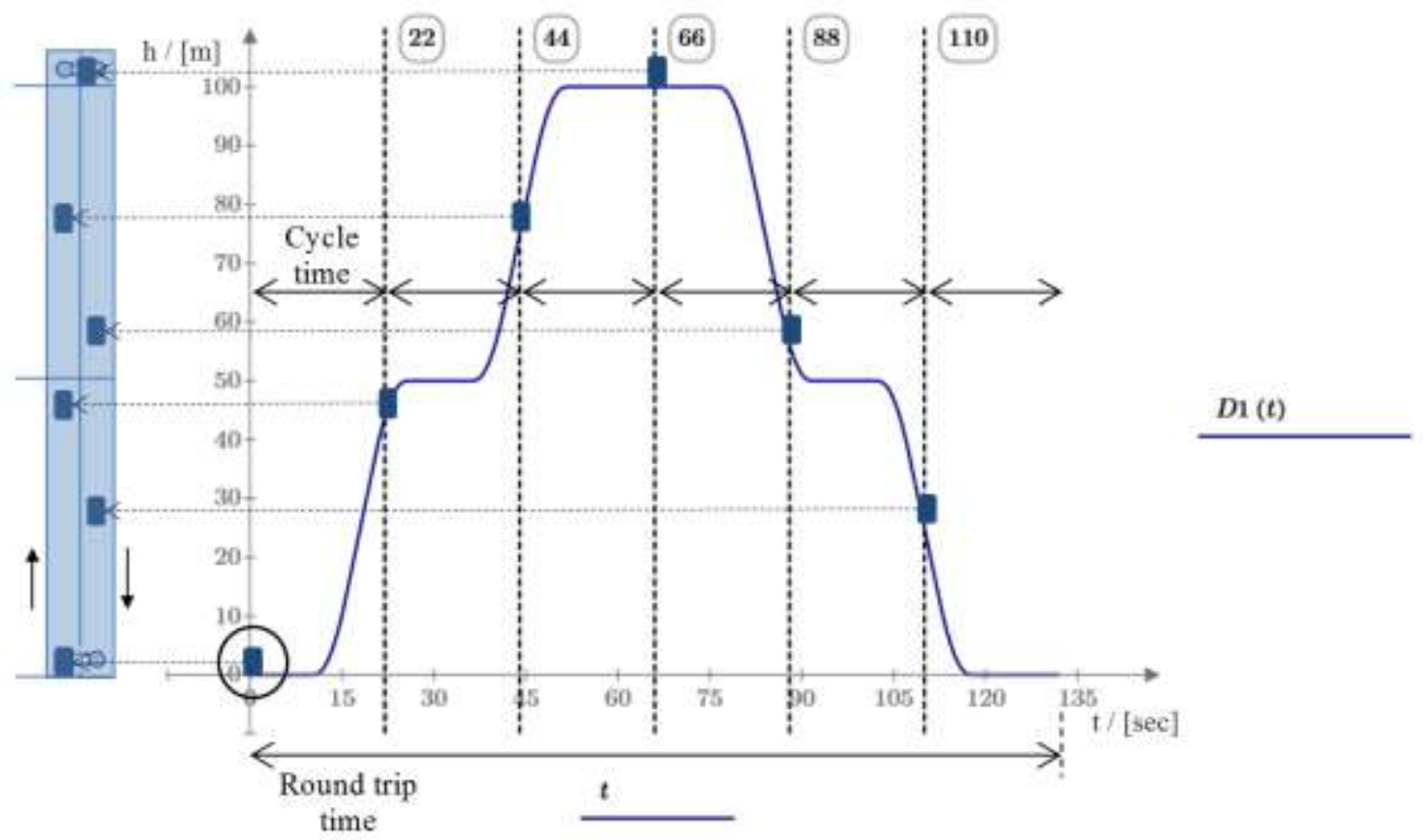

Figure 12: Cycle time, RTT and number of cabins

It is only possible to put an integer number of cars into the system. In case of an unchanged round trip time (RTT) and rounding down the number of cars/the result of equation (7) the real average cycle time $\left(\mathrm{t}_{\mathrm{CyR}}\right)$ will be higher than the minimum possible cycle time (see equation $(8)$ ). To achieve the same handling capacity the round trip time (RTT) needs to be reduced e.g. by increasing the speed of the cars.

$$
t_{C y R}=\frac{R T T}{N_{C}}
$$

In case of rounding up the number of cabins/the result of equation (7) the average minimum possible cycle time cannot be reduced because it is limited to a minimum. The RTT needs to be increased according to equation (9) to avoid traffic jams e.g. by reducing the speed of the cars.

$$
R T T=N_{C} * t_{C y}
$$




\section{QUALITY OF SERVICE}

As the major measure of quality of service is waiting time, the waiting time derived from the cycle time and interval may be the main measure [11], but travelling times and the number of stops need to be considered too. In multi car applications additional delays may be included as quality measures [19].

The maximum HC5 for conventional rope elevators is achieved in a two stop shuttle application. The RTT is kept to a minimum. Using RTT calculations the quality of service, interval and waiting time can be optimised.

For a circulating MCLS the HC5 is independent from the number of stops. Also the waiting time e.g. in the main entrance can be kept to a minimum, but additional delays during the journey will affect quality of service. In applications where all cabins have the same stops these additional delays can be reduced to a minimum, or completely avoided, through synchronisation of the cars. This can be compared with an underground train for urban transportation. Every train of a specific line has the same stops with a similar stop time. If one train cannot pass another train additional delays can be avoided during normal operation of the system.

Allowing individual stops for each car limits the options to avoid these delays without sacrificing HC5 as cars cannot pass each other. More sophisticated controls allocating passengers to cars can help improve the situation. This requires advanced passenger guidance, good indication and passenger awareness that cars loaded at the same landing door travel to different destination floors. This is unexpected by most lift passengers and could be confusing; it may be an option in the future.

Therefore the shuttle application with one or multiple sky lobbies is preferred as it ensures good quality of service with maximum possible handling capacity. 


\section{COMPARISON OF SHUTTLE LIFT SYSTEMS}

Consider a MCLS compared to traditional double deck lift systems in a shuttle lift application. Figure 13 shows the compared configurations. The comparison is based on the cycle time calculations for the MCLS described in this paper and RTT calculations for the double deck system. Different travel heights $(100 \mathrm{~m}, 200 \mathrm{~m}, 300 \mathrm{~m}, 400 \mathrm{~m}, 500 \mathrm{~m}$ and $600 \mathrm{~m})$ will be compared. Table 1 shows the parameters of both systems. It shows the number of passengers that actually fit in the car. The traffic split is $80 \%$ incoming and $20 \%$ outgoing passengers equally distributed to both lobbies. The MCLS has a $25 \%$ higher total HC5 compared to $100 \%$ incoming traffic as the minimum interval or cycle time is independent from additional down traffic. For the double deck system the additional transported down travelling passengers the roundtrip time and therefore the interval of the system is slightly increased compared to $100 \%$ incoming traffic because of longer total passenger transfer times during each stop (incoming and outgoing passengers). Figure 14 shows the chosen velocity and number of cabins and the total HC5 (number of passengers transported in 5 minutes in both directions with the given traffic split) and interval depending on travel height.

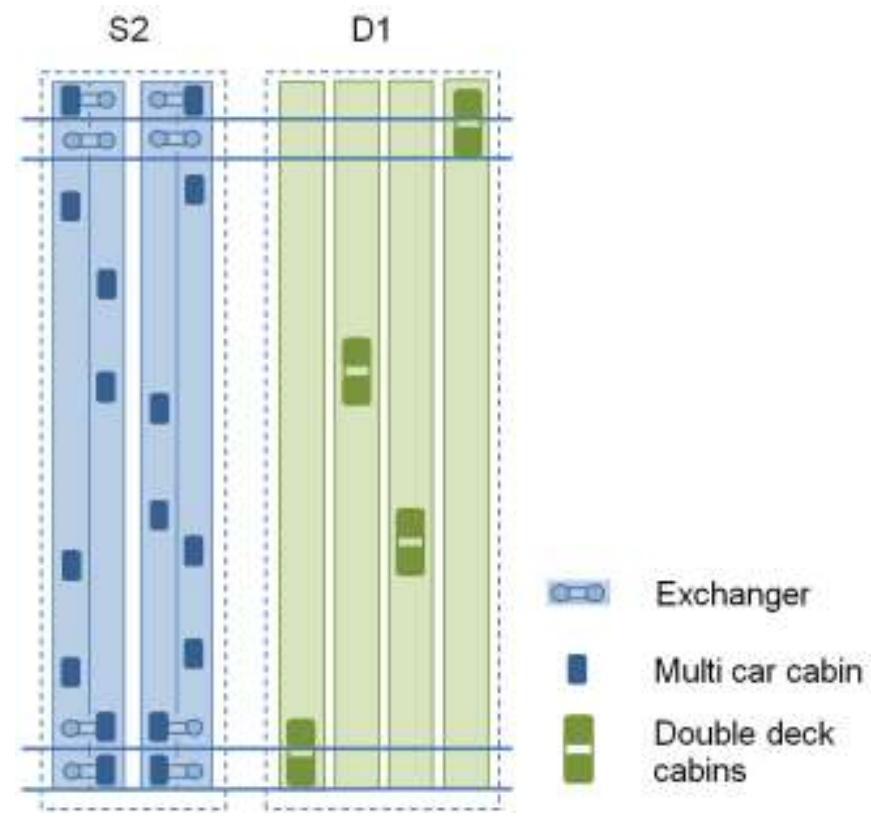

Figure 13: Comparison of a group of circulating multi car systems with a double deck group

Table 1: parameters of both systems

\begin{tabular}{|c|c|c|}
\hline & Double Deck & MCLS \\
\hline $\begin{array}{c}\text { Space shafts } \\
+ \text { waiting area }\end{array}$ & $\begin{array}{c}36 \mathrm{~m}^{2} \\
+18 \mathrm{~m}^{2}\end{array}$ & $\begin{array}{c}24 \mathrm{~m}^{2} \\
+12 \mathrm{~m}^{2}\end{array}$ \\
\hline Passenger/car & $2 \times 16$ & 8 \\
\hline Number of cabins & $2 \times 4$ & variable \\
\hline Velocity & variable & variable \\
\hline
\end{tabular}



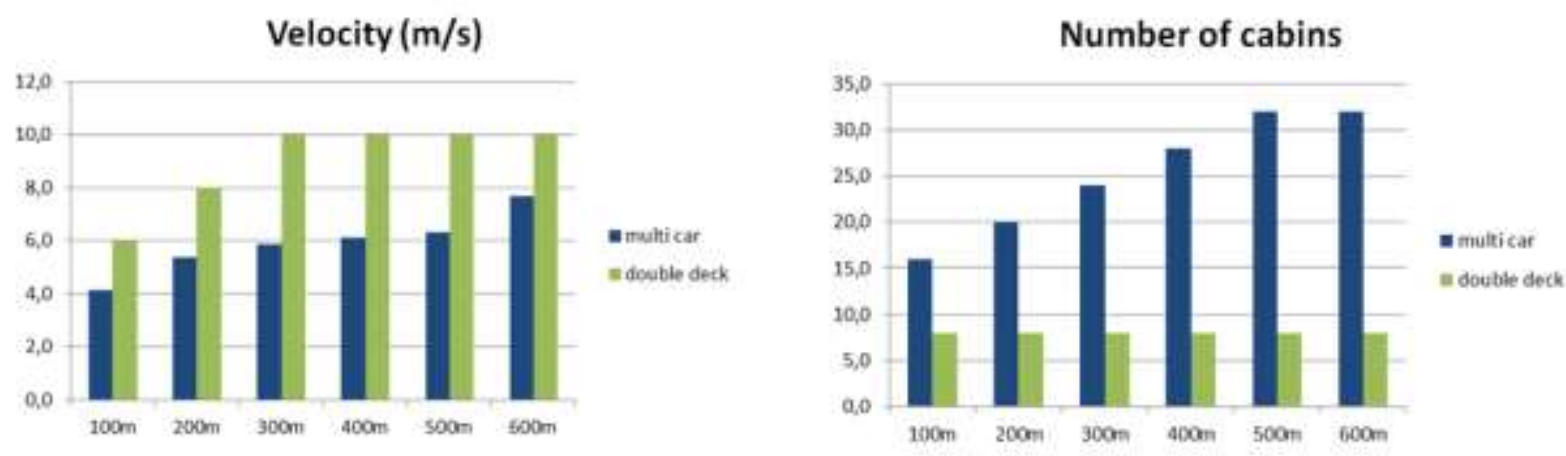

Handling capacity (passengers $/ 5 \mathrm{~min}$ )
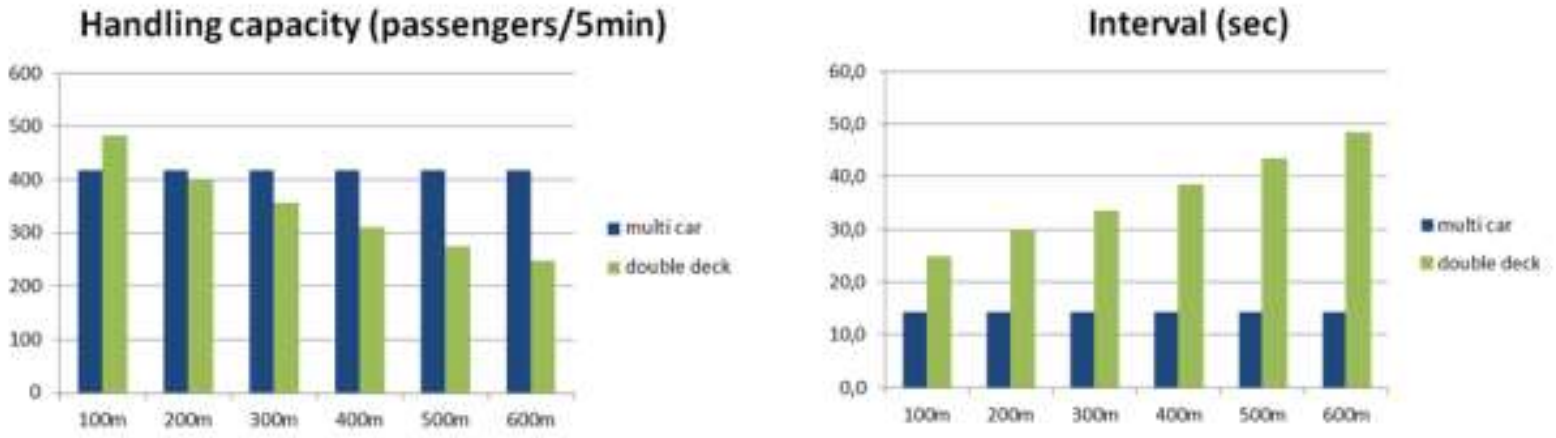

Figure 14: Comparison multi car vs. double deck depending on travel height: handling capacity, velocity, number of cabins and interval

The handling capacity of the multi car system is constant, independent from the travel height. An initial travel height of about $200 \mathrm{~m}$ is going to be higher than the comparable double deck system. With increasing travel height, the benefit of the circulating MCLS can be seen. To keep the handling capacity constant at the MCLS for every travel height the number of cabins required needs to be adapted for the MCLS without additional shafts. Without adding any shafts the number of cabins for the four double deck shafts is constant.

With increasing travel height the rated velocity is increased for both systems. The velocity of the MCLS is lower than the velocity of the double deck.

The average waiting time (AWT) and average transit time (ATT) of both systems is compared in Figure 15. The relationship between interval and waiting time is complex [20]. For simplicity, in these results the average waiting time of roundtrip time calculations is taken as $50 \%$ of the interval. 


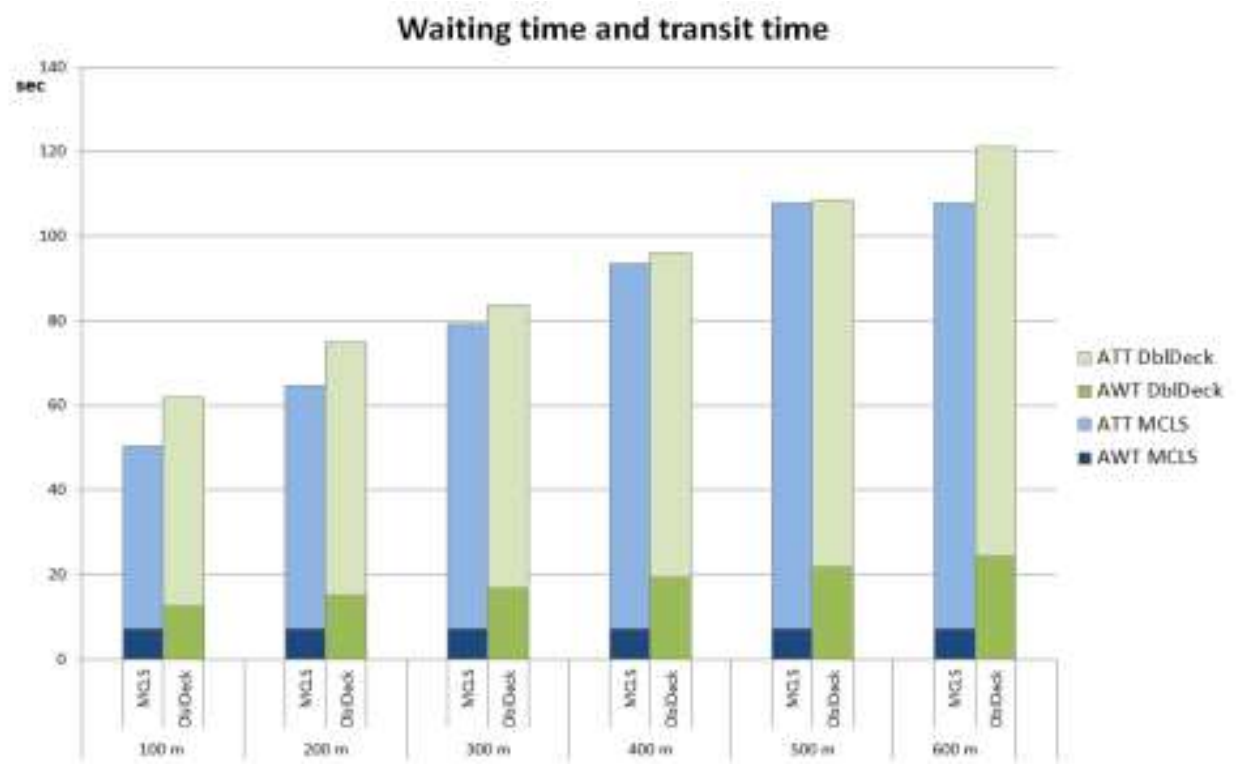

Figure 15: Comparison multi car vs. double deck depending on travel height: average waiting time (AWT) and average transit time (ATT)

Since the interval of the multi car is constant, the average waiting time is constant. Although the chosen velocity of the multi car is less than the double deck, the time to destination of the MCLS provides better values. This is caused by lower average waiting times and shorter passenger loading/unloading times.

\section{CONCLUSION}

Handling capacity for a circulating MCLS is based on the minimum possible cycle time of the system. The minimum possible cycle time of circulating MCLS is discussed and defined in this paper. If the average RTT of a MCLS increases the number of cars has to be adapted in order to keep the minimum possible cycle time and a constant handling capacity. To achieve the minimum possible cycle time without traffic jams the velocity is also adapted. Safety distances and stopping distances need to be calculated and considered in order to calculate reasonable values for the minimum possible cycle time.

Flexible arrangements using MCLSs as shuttle lifts can be included in the vertical transportation concept for tall buildings; this approach has been shown and described.

Based on a cycle time and RTT calculations a circulating MCLS and a double deck system are compared with different travelling heights in a shuttle application. The MCLS provides constant values for handling capacity and average waiting time with increasing travelling heights by adding more cars to the system. Also a short cycle time enables short average waiting time.

These values need to be proven by simulation. Also advanced control algorithms may enable additional MCLS applications. 


\section{REFERENCES}

[1] Gerstenmeyer, S. and Peters, R. (2015) Lifts without ropes: how many shafts and cars are needed? In: Symposium on Lift and Escalator Technologies. Northampton:

[2] Jetter, M. and Gerstenmeyer, S. (2015) A Next Generation Vertical Transportation System. In: Wood, A. \& Gabel, J. (eds.), The Future of Tall: A Selection of Written Works on Current Skyscraper Innovations. Addendum to the Proceedings of the CTBUH 2015 International Conference, New York, 26-30 October 2015. Chicago: Council on Tall Buildings and Urban Habitat.

[3] Thumm, G. (2004) A breakthrough in lift handling capacity. In: Elevator Technology 14, Proceedings of Elevcon 2004. The International Association of Elevator Engineers.

[4] Elevator World (2015) The elevator museum - timeline [online]. Available from: http://www.theelevatormuseum.org/timeline.php [Accessed 05/11, 2015].

[5] Strakosch, G. and Caporale, R. (2010) The Vertical Transportation Handbook, Fourth Edition. Hoboken; New Jersey: John Wiley \& Sons, Inc.

[6] Elevator World, (1996) An elevator go round. Elevator World, (January), pp. 42

[7] Jappsen, H. (2002) High Rise Elevators For The $21^{\text {st }}$ Century. In: Elevator Technology 12, Proceedings of Elevcon 2002. The International Association of Elevator Engineers.

[8] Godwin, A. (2010) Circular transportation in the $21^{\text {st }}$ century (without the 'beautiful' counterweight!). In: Elevator Technology 18, Proceedings of Elevcon 2010. The International Association of Elevator Engineers.

[9] So, A., Al-Sharif, L. and Hammoudeh, A. (2014) Analysis of Possible Two Dimensional Elevator Traffic Systems in Large Buildings. In: Elevator Technology 20, Proceedings of Elevcon 2014. The International Association of Elevator Engineers.

[10] So, A., Al-Sharif, L. and Hammoudeh, A. (2015) Traffic analysis of a simplified twodimensional elevator system. Building Services Engineering Research and Technology. 36 (5), $567-$ 579.

[11] CIBSE (2010) CIBSE Guide D: 2010 Transportation Systems in Buildings. London: The Chartered Institution of Building Services Engineers.

[12] Müller, J. (2014) Lift Systems in High-Rise Buildings: Handling Capacity and Energy Efficiency. In: Symposium on Lift and Escalator Technologies. Northampton:

[13] Siikonen, M. (1997) Planning and Control Models for Elevators in High-Rise Buildings. Research Reports A68. Helsinki University of Technology, Systems Analysis Laboratory. 
[14] ThyssenKrupp Elevator AG (2014) New era of elevators to revolutionize high-rise and midrise construction [online]. Available from: http://www.urban-hub.com/ideas/new-era-of-elevatorsto-revolutionize-high-rise-and-mid-rise-construction/ [Accessed 04/20, 2015].

[15] Smith, A. (2016) Engineers cut lose as ropeless lifts enter space race [online]. Available from: http://www.cibsejournal.com/technical/engineers-cut-lose-as-ropeless-lifts-enter-space-race/ [Accessed 01/08, 2016].

[16] Scott, A. (2016) Are we ready for the ropeless lift?[online]. Available from: http://www.cibsejournal.com/technical/engineers-cut-lose-as-ropeless-lifts-enter-space-race/ [Accessed 01/08, 2016].

[17] Kaczmarczyk, S. (2008) The dynamic response of elevator compensating ropes in high-rise buildings. In: Elevator Technology 17. The International Association of Elevator Engineers.

[18] Gerstenmeyer, S. and Peters, R. (2016) Safety distance control for multi-car lifts. Building Services Engineering Research and Technology [online], Available from: http://bse.sagepub.com/cgi/content/abstract/0143624416642266v1 [Accessed 06/06, 2016].

[19] Smith, R. and Gerstenmeyer, S. (2013) A review of Waiting Time, Journey Time and Quality of Service. In: Symposium on Lift and Escalator Technologies. Northampton:

[20] Peters, R. (2013) The Application of Simulation to Traffic Design and Dispatcher Testing. In: Symposium on Lift and Escalator Technologies. Northampton: 


\section{ACKNOWLEDGMENTS}

This work was done as a part of post graduated research study at The University of Northampton supported by the thyssenkrupp Elevator.

Source of Figure 6, Figure 1 and Figure 9: thyssenkrupp 